\title{
PENGARUH PENERAPAN ADVANCED MANUFACTURING TECHNOLOGY DAN OPERATIONS IMPROVEMENT PRACTICES TERHADAP KOMPETENSI FLEXIBLE MANUFACTURING PT XYZ
}

\author{
Robert Gorevi Sanjaya \\ Program Studi Magister Manajemen Universitas Tarumanagara \\ robert.gorevi@gmail.com \\ Carunia Mulya Firdausy \\ Program Studi Magister Manajemen Universitas Tarumanagara
}

Masuk : 01-06-2020, revisi : 26-06-2020 diterima untuk diterbitkan : 26-06-2020

\begin{abstract}
The development of the manufacturing nowadays has become very dynamic, as companies are required to be more flexible in order to maintain the sustainability of their business. However, this requirement has not been fulfilled by PT XYZ. Due to this reason, this study aims at examining whether 1) the Advanced Manufacturing Technology (AMT) has a positive effect on Flexible Manufacturing Competency (FMC); 2) the Operations Improvement Practices (OIP) has a positive effect on Flexible Manufacturing Competency (FMC); 3) the AMT can mediate the effect between OIP and FMC; and 4) the OIP can moderate the influence between AMT and FMC. Primary data were obtained from distributing questionnaires to 112 head of department and senior staff of PT XYZ, which were selected by purposive sampling to employees who were directly related to the production process. Data processing techniques used was partial least square (PLS) analysis which processed through the smartPLS 3 program. The results showed that 1) the AMT variable had a positive effect on FMC 2) the OIP variable had a positive effect on FMC 3) the AMT variable mediated the effect between OIP and FMC, and 4) the OIP variable moderated the effect between AMT and FMC.
\end{abstract}

Abstrak: Perkembangan dunia manufaktur saat ini sudah menjadi sangat dinamis. Akibatnya perusahaan dituntut untuk dapat lebih fleksibel agar dapat menjaga keberlangsungan bisnisnya. PT XYZ merupakan perusahaan otomotif (roda dua) yang belum sepenuhnya memperhatikan kompetensi fleksibilitas manufaktur (FMC). Oleh karena itu, studi ini bertujuan menguji apakah 1) Advanced Manufacturing Technology (AMT) berpengaruh positif terhadap FMC; 2) Operations Improvement Practices (OIP) berpengaruh positif terhadap FMC; 3) AMT dapat memediasi pengaruh antara OIP dan FMC; serta 4) OIP dapat memoderasi pengaruh antara AMT dan FMC. Data primer diperoleh dari pembagian kuesioner kepada 112 kepala bagian dan staff senior PT XYZ, yang dipilih secara purposive sampling yaitu kepada karyawan yang berkaitan langsung dengan proses produksi. Teknik pengolahan data menggunakan analisa partial least square (PLS) yang diproses melalui program smartPLS 3. Hasil penelitian menunjukkan bahwa 1) variabel AMT berpengaruh positif terhadap FMC 2) variabel OIP berpengaruh positif terhadap FMC 3) variabel AMT memediasi pengaruh antara OIP dan FMC, serta 4) variabel OIP memoderasi pengaruh antara AMT dan FMC.

Keywords: Flexible Manufacturing Competency (FMC), Operation Improvement Practices (OIP), Advanced Manufacturing Technology (AMT)

\section{PENDAHULUAN}

Perkembangan dunia manufakur saat ini sudah menjadi sangat dinamis, akibatnya para pelaku industri manufaktur dituntut untuk bisa beradaptasi menjadi lebih reseptif dan fleksibel. Upton (1995) dalam Zhang et al (2006) menerangkan fleksibilitas sebagai peningkatan 
ketersediaan produk, dengan memperbaiki kemampuan perusahaan untuk merespon cepat, dan mendapatkan performa yang baik dalam menghasilkan berbagai jenis produk.

Zhang et al. (2002) dalam Zhang et al. (2006) membagi konsep fleksibel manufaktur menjadi 2 yaitu Flexible Manufacture Capability dan Flexible Manufacture Competency. Flexible Manufacture Capability adalah kemampuan untuk beradaptasi terhadap perubahan eksternal seperti kompetisi, dan pemintaan konsumen. Sedangkan Flexible Manufacture Competency (FMC) adalah kemampuan adaptasi mesin, tenaga kerja, material handling, dan jalur distribusi untuk menghadapi perubahan-perubahan yang menjadi kunci internal dalam menghadapi kompetisi.

Beberapa peneliti menyatakan bahwa praktek-praktek perbaikan operasi (OIP), seperti set-up redesign dan preventive maintenance dapat meningkatkan FMC (Cagliano \& Spina, 2000; Delbridge \& Barton, 2002; Hottenstein et al., 1999; Jonsson, 2000; Cao et al., 1998; Koufteros et al., 1998; Lewis \& Boyer, 2002; Small \& Chen, 1997; Udo \& Ebiefung, 1999; Upton \& Kim, 1998; Yauch \& Steudel, 2002 dalam Zhang et al. 2006). Beberapa peneliti lainnya menyarankan aplikasi dari advanced manufacturing technology (AMT) pada design, planning, dan manufacturing dapat meningkatkan FMC (Boyer et al., 1996; Kotha \& Swamidass, 2000; Lau, 1999; Lei \& Goldhar, 1991; Small \& Chen, 1997b; Sun, 2000 dalam Zhang et al. 2006). Namun kaitan antara OIP dan AMT terhadap peningkatan FMC masih belum banyak diteliti (Zhang, Vonderembse, \& Cao, 2006).

PT XYZ merupakan sebuah perusahaan yang bergerak dibidang otomotif khususnya roda dua. Produk yang dihasilkan PT XYZ cukup bervariasi dari model sepeda motor $c u b$, skutik (scooter matic), sport, hingga adventure. Setiap pabrik yang dimiliki PT XYZ hanya mampu memproduksi beberapa jenis model tertentu saja, artinya sistem manufaktur PT XYZ belum memiliki kompetensi yang fleksibel. Padahal dewasa ini kompetensi manufaktur yang fleksibel sudah menjadi keharusan untuk dapat sustain dalam bisnis yang makin dinamis. Penelitian ini dilakukan dengan tujuan untuk mengetahui beberapa strategi yang dapat dilakukan PT XYZ untuk meningkatkan kompentensi fleksibilitas manufakturnya, seperti investasi teknologi (AMT), maupun memperbaiki sistem / budaya kerja di operasional (OIP).

\section{TELAAH KEPUSTAKAAN}

Berbagai studi terkait masalah ini telah banyak dilakukan. Dalam studi-studi tersebut diungkapkan pentingnya perusahaan memiliki kompetensi manufaktur yang fleksibel (FMC). Salah satu caranya yakni dengan menerapkan strategi peningkatan teknologi manufaktur (AMT). Dengan adanya strategi ini, perusahaan dapat mampu menghasilkan produk yang bervariasi sesuai dengan keinginan konsumen (Boyer et al., 1996; Gerwin \& Kolodny, 1992; Lei et al., 1996; Meredith, 1987; Saraph \& Sebastian, 1992; Small \& Chen, 1997b dalam Zhang et al. 2006). Selain itu juga diungkapkan bahwa tanpa aplikasi AMT, perusahaan tidak dapat mencapai tingkat integrasi manufaktur yang tinggi dan akan kehilangan kesempatan meningkatkan FMC (Zhang, Vonderembse, \& Cao, 2006).

Namun strategi AMT dalam prakteknya, tidak dapat berjalan sendiri, namun juga harus diimbangi oleh strategi perbaikan yang berkelanjutan (OIP) atau continuous improvement. Fokus dari perbaikan berkelanjutan ini adalah untuk memotivasi karyawan untuk dapat berdampak mulai dari hal kecil dalam perbaikan proses operasional perusahaan (Imai, 1986 dalam Zhang et al., 2006). Aplikasi OIP juga memiliki pengaruh positif terhadap FMC perusahaan, sebagaimana beberapa penelitian terdahulu telah menguji korelasi kedua variabel tersebut (Cagliano \& Spina, 2000; Delbridge \& Barton, 2002; Hottenstein et al., 1999; Jonsson, 2000; Co et al., 1998; Koufteros et al., 1998; Lewis \& Boyer, 2002; Small \& Chen, 1997a; Udo \& Ebiefung, 1999; Upton \& Kim, 1998; Yauch \& Steudel, 2002; dalam Zhang et al., 2006).

Bagi perusahaan yang sudah menerapkan budaya continous improvement dalam praktek kerjanya, perlu juga menambahkan investasi berupa teknologi yang dapat menunjang kompetensi fleksibilitas perusahaannya. Savolainen (1999) dan Sim (2001) dalam Zhang et al. 
(2006) menjelaskan bahwa pencapaian kompetensi fleksibilitas manufaktur suatu perusahaan dapat berbeda-beda dikarenakan adopsi OIP akan berkelanjutan pada penerapan teknologi tinggi di perusahaan tersebut, sehingga dapat dikatakan perusahaan tidak akan bisa mencapai tingkatan integrasi tertinggi dalam manufaktur tanpa adanya penerapan teknologi tinggi pula.

\section{Hipotesis Penelitian}

Hipotesis penelitian ini terdiri dari 4 hipotesis sebagai berikut:

H1 : AMT berpengaruh positif terhadap FMC PT XYZ.

$\mathrm{H} 2$ : OIP berpengaruh positif terhadap FMC PT XYZ.

H3 : AMT memediasi pengaruh antara OIP dan FMC PT XYZ.

H4 : OIP memoderasi pengaruh antara AMT dan FMC PT XYZ.
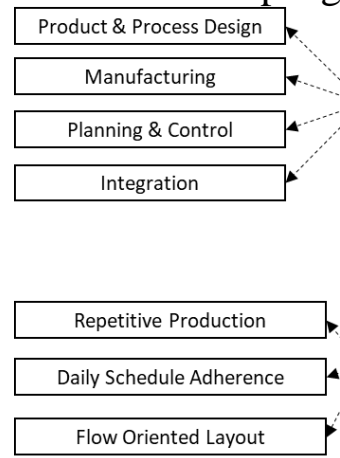

Flow Oriented Layout
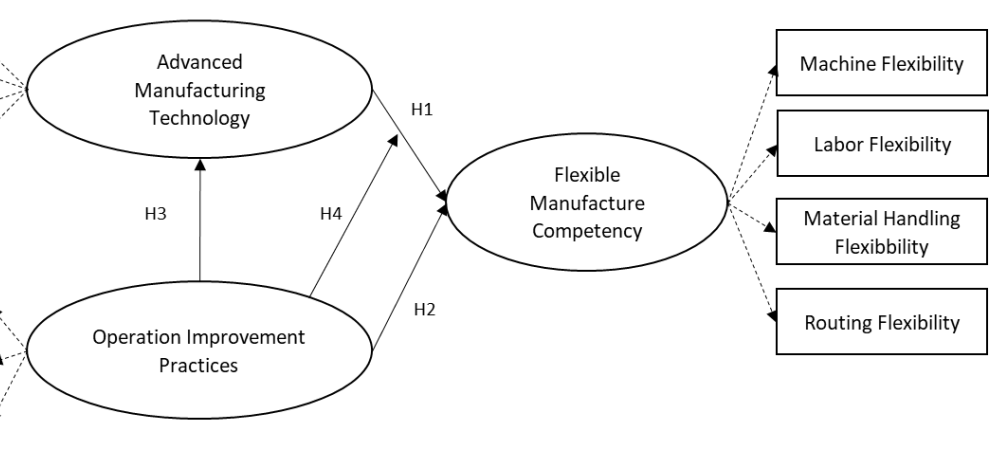

\section{Gambar 1 \\ Model Penelitian}

\section{METODOLOGI PENELITIAN}

\section{Sumber \& Data Pengumpulan}

Sumber data penelitian diperoleh dari karyawan yang memahami terkait proses produksi dan penerapan teknologi di tiga pabrik PT XYZ yang terletak di Sunter, Cikarang, dan Karawang. Jumlah karyawan yang menjadi sample penelitian ini sebanyak 112 responden. Responden tersebut antara lain terdiri dari kepala seksi produksi (46 orang), koordinator engineering (33 orang), serta staff senior engineering (33 orang) dari 3 pabrik (Sunter, Cikarang \& Karawang) PT XYZ. Cara mengumpulkan data primer tersebut yakni dengan melalui penyebaran kuesioner.

\section{Operasionalisasi Variabel Penelitian}

Variabel penelitian yang digunakan dalam penelitian ini ada 3 yaitu, 2 variabel independen (AMT \& OIP), serta 1 variabel dependen (FMC). Variabel atau konstruk dalam penelitian ini memiliki sifat refleksif, yaitu arah indikatornya dari variabel menuju indikator. Pengukuran indikator dilakukan dengan menggunakan pertanyaan kuisioner dengan tipe closed question yakni dimana responden diminta untuk menjawab berdasarkan alternatif yang sudah ditentukan oleh peneliti. Pengukuran skala indikator menggunakan skala interval Likert 5 poin yaitu "sangat tidak setuju", "tidak setuju", "netral", "setuju", serta "sangat setuju".

\section{Metode Analisis}

Setelah data diatas diperoleh, langkah selanjutnya yakni melakukan analisis yang terdiri dari analisa model langsung, analisa model mediasi, dan analisa model moderasi menggunakan software smartPLS 3. Untuk setiap analisa model, dilakukan 3 kali pengujian yaitu: pengujian outer model, pengujian inner model, serta pengujian indeks kualitas (Ghozali, 2015). Pengujian outer model dilakukan dengan melihat nilai validitas konvergen (loading factor, AVE, communality), validitas diskriminan (cross loading, HTMT), serta reliabilitas (cronbach's alpha, composite reliability). Pengujian inner model dilakukan dengan melihat nilai $R^{2}$, effect size $f^{2}, Q^{2}$ predictive relevance, serta signifikansi (two-tailed). Sedangkan pengujian indeks kualitas dilakukan dengan melihat nilai communality index, redundancy index, dan goodness of fit (GoF) index. 
Untuk analisa mediasi, penelitian ini menggunakan metode yang direkomendasikan oleh Preacher \& Hayes (2008) yaitu the bootstrap method serta menghitung nilai VAF (variance accounted for) dengan nilai yang direkomendasikan oleh Hair et al (2014) dalam Hadi et al. (2016) adalah $>80 \%$ (mediasi sempurna), antara 20\% dan $80 \%$ (mediasi sebagian) dan dibawah $20 \%$ (tidak ada efek mediasi). Sedangkan pengujian moderasi menggunakan metode two-stage approach yang memiliki kekuatan prediksi yang tinggi (Becker, 2006), dimana kemudian dihitung nilai $f^{2}$ perbandingan antara nilai pengaruh sebelum ada efek moderasi dan setelah ada efek moderasi, berdasarkan saran dari Henseler (2010) dalam Ghozali (2015).

\section{ANALISA PEMBAHASAN}

\section{Hasil Uji Statistik}

Pada pengujian model langsung diperoleh bahwa AMT berpengaruh positif dan signifikan terhadap FMC. Hasil yang signifikan tersebut diikuti dengan model yang kuat $\left(\mathrm{R}^{2}>\right.$ 0,75 ) dan kualitas model yang baik (GoF indeks > 0,36), namun untuk efek pengaruh yang cenderung kecil $\left(\mathrm{f}^{2}<0,15\right)$. Selain itu juga diperoleh bahwa OIP berpengaruh positif dan signifikan terhadap FMC. Hasil yang signifikan tersebut diikuti dengan model yang kuat $\left(\mathrm{R}^{2}>\right.$ $0,75)$ dan kualitas model yang baik (GoF indeks $>0,36)$, dan efek pengaruh yang cenderung besar $\left(\mathrm{f}^{2}>0,35\right)$.

Untuk pengujian model mediasi, hasil studi ini menunjukkan bahwa AMT berperan dalam memediasi pengaruh antara OIP dan FMC. Hasil tersebut didapatkan dari metode bootstrap melalui komparasi hasil path coefficient dari model langsung dan model mediasi. Nilai VAF yang didapatkan dari model mediasi ini (27\%) juga masih masuk dalam range mediasi oleh Hair et al. (2014) dalam Hadi et al. (2016), yaitu diantara angka 20\% sampai 80\%. Meskipun demikian, besarnya efek mediasi parsial ini bisa dikatakan kecil, terbukti nilai VAF yang hanya $27 \%$, artinya efek mediasi yang terjadi hanya sebesar $27 \%$ dari total efek yang terjadi.

Demikian pula, dalam pengujian model moderasi, juga diperoleh bahwa OIP berpengaruh secara signifikan memoderasi pengaruh antara AMT dan FMC. Hasil pengujian moderasi menunjukkan efek moderasi semu / quasi moderation yaitu variabel moderasi selain secara signifikan memoderasi hubungan, tapi juga secara signifikan berpengaruh langsung terhadap variabel FMC. Nilai effect size $\mathrm{f}^{2}: 0,76$ juga menunjukkan efek interaksi moderasi yang kuat $(>0,35)$. Lihat Tabel 1.

\section{Tabel 1}

Hasil Pengujian Statistik

\begin{tabular}{|c|c|c|c|c|c|c|}
\hline & $\begin{array}{l}\text { T- } \\
\text { Statistic }\end{array}$ & $\mathbf{R}^{2}$ & $\begin{array}{l}\text { Effect Size } \\
\mathbf{f}^{2}\end{array}$ & $\begin{array}{l}\text { GoF } \\
\text { Index }\end{array}$ & Mediation & Moderation \\
\hline AMT -> FMC & 3,243 & \multirow{2}{*}{$\begin{array}{l}0,82 \\
8\end{array}$} & 0,084 & \multirow{2}{*}{0,7048} & - & - \\
\hline OIP -> FMC & 7,721 & & 0,469 & & - & - \\
\hline $\begin{array}{l}\text { OIP } \quad \text {-> AMT } \\
\text { FMC }\end{array}$ & 3,172 & $\begin{array}{l}0,82 \\
8\end{array}$ & 0,471 & 0,7009 & $\begin{array}{l}\text { Mediasi parsial, VAF : } \\
27 \%\end{array}$ & - \\
\hline AMT*OIP -> FMC & 8,986 & $\begin{array}{l}0,90 \\
0\end{array}$ & 0,728 & 0,7937 & - & $\begin{array}{l}\text { Quasi } \\
\text { Moderation, } \\
f^{2}: 0,76\end{array}$ \\
\hline
\end{tabular}

Hasil penelitian didukung oleh penelitian dari Zhang et al. (2006) yang memiliki hasil yang sama. Shaiken (1985) dalam Zhang et al. (2006) menjelaskan lebih lanjut bahwa penerapan AMT sendiri tidak akan berdampak banyak terhadap FMC perusahaan. Hal ini karena masih membutuhkan sentuhan "human factor". Ini berarti perlunya perbaikan sistem kerja untuk lebih meningkatkan pencapaian perusahaan dalam mencapai kompetensi manufaktur yang fleksibel.

Pengaruh positif dan signifikan OIP terhadap FMC juga didukung oleh penelitian dari Zhang et al. (2006). Temuan ini mengindikasikan bahwa apabila setiap karyawan sudah memiliki budaya improvement yang berkelanjutan, maka akan terbentuk suatu tim kerja yang memiliki tenaga kerja yang multi-skill dan fasilitas kerja yang fleksibel untuk mencapai hasil 
kerja yang efisien dan variasi produk yang tinggi (Cooney 2002, Naylor et al., 1999, White 1996, dalam Zhang et al., 2006).

Peran AMT yang signifikan dalam memediasi pengaruh antara OIP dan FMC juga didukung oleh penelitian dari Vita (2018). Penerapan teknologi tinggi (industry 4.0) akan membangkitkan prinsip kerja lean manufacturing yang akan berujung pada tercapainya performa manufaktur yang fleksibel (Vita, 2018).

Peran OIP yang signifikan dalam memmoderasi pengaruh antara AMT dan FMC juga didukung oleh penelitian dari Zhang et al. (2006). Delbridge dan Barton, 2002; Savolainen, 1999 dalam Zhang et al., 2006 juga menjelaskan bahwa kompetensi fleksibilitas manufaktur suatu perusahaan tidak diawali dari teknologi yang tinggi, tapi dari "human factor" yaitu kemampuan karyawan / operator dalam melakukan perbaikan / re-design suatu sistem manufaktur dan fasilitasnya.

\section{Implikasi dari temuan penelitian ini sebagai berikut.}

Integrasi antara AMT dan OIP akan meningkatkan pencapaian operasional suatu perusahaan seperti biaya yang rendah, kualitas yang tinggi, dan fleksibilitas manufaktur (Vita, 2018). Sanders et al. (2016) dalam Vita (2018) menjelaskan bahwa dengan adanya adaptasi perusahaan terhadap teknologi tinggi dalam industry 4.0, maka perusahaan yang telah memiliki budaya kerja OIP / lean manufacturing yang tinggi akan lebih berpotensi besar dalam mendapatkan operational excellence.

Adaptasi industry 4.0 dewasa ini sudah tidak bisa ditawar, perusahaan yang ingin sustain atau memiliki keberlangsungan di masa yang akan datang perlu mengadaptasi konsep indusrty 4.0, demikian juga PT XYZ. Kupper et al. (2017) dalam Vita (2018) menjelaskan bahwa untuk mendapatkan manfaat yang optimal dari penerapan teknologi tinggi industry 4.0, maka PT XYZ perlu menerapkan konsep OIP atau lean manufacturing secara maksimal.

\section{KESIMPULAN DAN SARAN}

Hasil studi ini menunjukkan beberapa kesimpulan sebagai berikut :

a. Advanced Manufacturing technology (AMT) berpengaruh positif terhadap kompetensi manufaktur yang fleksibel (FMC) PT XYZ.

b. Operations Improvement Practices (OIP) berpengaruh positif terhadap kompetensi manufaktur yang fleksibel (FMC) PT XYZ.

c. Advanced Manufacturing technology (AMT) memediasi pengaruh antara Operations Improvement Practices (OIP) dan terhadap kompetensi manufaktur yang fleksibel (FMC) PT XYZ.

d. Operations Improvement Practices (OIP) memoderasi pengaruh antara Advanced Manufacturing technology (AMT) dan terhadap kompetensi manufaktur yang fleksibel (FMC) PT XYZ.

\section{Implikasi Manajerial}

Implikasi manajerial dari studi ini yakni PT XYZ perlu melakukan investasi pada bidang teknologi secara masif, terutama untuk beberapa pabrik yang masih menggunakan teknologi yang konvensional. Namun sebelum mengadopsi teknologi yang tinggi, perusahaan sebaiknya mempersiapkan sistem kerja dan kompetensi tenaga kerjanya yaitu budaya continous improvement.

\section{DAFTAR PUSTAKA}

Becker J. M., (2006, 28 Maret). Re: PLS 3-Choosing options for Moderators. Diakses pada 30 Maret 2020, dari https://forum.smartpls.com/viewtopic.php?t=15405

Ghozali, I., \& Latan, H. (2015). Partial Least Squares Konsep, Teknik, dan Aplikasi Menggunakan Program SmartPLS 3.0 Untuk Penelitian Empiris ( $2^{\text {nd }}$ ed.). Semarang, ID: Badan Penerbit Undip. 
Hadi, N. U., Abdullah, N., \& Sentosa, I. (2016). Making sense of mediating analysis: A marketing perspective. Review of Integrative Business and Economics Research, 5(2), 62.

Preacher, K. J., \& Hayes, A. F. (2008). Asymptotic and resampling strategies for assessing and comparing indirect effects in multiple mediator models. Behavior Research Methods, $40(3), 879-891$.

Vita, R. O. (2018). Integration of industry 4.0 and lean manufacturing and the impact on organizational performance.

Zhang, Q., Vonderembse, M. A., \& Cao, M. (2006). Achieving flexible manufacturing competence. International Journal of Operations \& Production Management, 26(6), 580-599. doi:10.1108/01443570610666957 